Z. klin. Chem. u. klin. Biochem.

8. Jg., S. $488-491$, September 1970

\title{
Mikrolipidanalysen aus Serum mit dem Eppendorfsystem 3000)
}

\author{
Von H. Egge, U. Murawski, J. Müller und F. Zilliken \\ Aus dem Pbysiologisch-Chemischen Institut der Universität Bonn ' '
}

(Eingegangen am 12. Mai 1970)

Es wird über eine Methode berichtet, die es erlaubt, aus Serum Lipidbestimmungen im Mikromaßstab (Gesamtlipid, freies und verestertes Cholesterin, Triglyceride, freie Fettsäuren und Phospholipide) mit hoher Genauigkeit und Schnelligkeit praktisch in einem Arbeitsgang durchzuführen. Die erforderlichen Serummengen betragen $20 \mathrm{bzw} .50 \mu \mathrm{l}$ für eine Bestimmung. Die Bestimmung der Gesamtlipide erfolgt gravimetrisch an einer elektrischen Mikrowaage. Der Variationskoeffizient beträgt $\leqq 2 \%$. Durch Einbeziehen des Eppendorf-Mikroliter-Systems 3000 gelingt es, eine größere Anzahl von Seren gleichzeitig zu analysieren. Die Lipidverteilung wird mittels Dünnschichtchromatographie auf Objektträgern in 3 Laufmittelsystemen fallender Polarität ermittelt. Die Wahl der Lösungsmittel erlaubt eine optimale Trennung aller Komponenten. Diese werden nach Verkohlen unter standardisierten Bedingungen densitometrisch vermessen. Die Variationskoeffizienten betragen für Phospholipide, Triglyceride und Cholesterinester $\leqq 5 \%$, für Cholesterin und freie Fettsäuren $\leqq 10 \%$.

The microanalysis of serum lipids with the Eppendorfsystem 3000

A method is presented for the determination of serum lipids (total lipid, cholesterol, cholesterol esters, phospholipids, free fatty acids and triglycerides) on a microscale with a high accuracy and rate of operation. The amount of serum necessary for one determination is $20 \mu l$ or $50 \mu l$. Total lipid is determined gravimetrically on an electrical microbalance. The variation coefficient is $\leqq 2 \%$. By using the Eppendorf microliter system 3000 a larger number of samples can be assayed simultaneously. Distribution of the individual classes of lipids are determined by thin layer chromatography on microchromatoplates employing a three solvent system of decreasing polarity. The choice of solvent systems allows an optimal separation of serum lipid classes involved. After charring with $10 \%$ sulfuric acid under standardized conditions, the distribution of lipids is measured densitometrically. The variation coefficient for the determination of phospholipids and cholesterolesters is $\leqq 5 \%$ and $10 \%$ for cholesterol and free fatty acids.

Zur Charakterisierung der verschiedenen Formen der Lipaemien ist die Aufstellung eines exakten Serumlipidstatus unerläßlich. Hierfür bieten sich verschiedene $\mathrm{Me}$ thoden an (1-7). Fast alle zitierten Methoden sind jedoch relativ zeitraubend. Wir haben seit längerem Lipide dünnschichtchromatographisch in Anlehnung an vaN GENT (8) bestimmt. Es war daher naheliegend, diese Methode auch für klinische Serumanalysen anzuwenden. In einem Arbeitsgang werden Phosphatide, freie Fettsäuren, Cholesterin, Neutralfette und Cholesterinester und deren Verteilung densitometrisch quantitativ bestimmt. Vom Auftragen des Lipidgemisches auf die Dünnschichtplatte bis zum fertigen Densitogramm werden etwa $45 \mathrm{Min}$. benötigt.

Da für die Dünnschichtchromatographie nur sehr geringe Lipidmengen erforderlich sind $(5-7 \mu \mathrm{g}$ für ein Chromatogramm), wurde eine Mikromethode ausgearbeitet, die es erlaubt, aus $20 \mathrm{bzw}$. $50 \mu \mathrm{l}$ Serum eine exakte Gesamtlipidbestimmung vorzunehmen. Die Lipide werden aus dem Serum nach Forch (9) extrahiert. Anschließend wird ein aliquoter Teil gravimetrisch bestimmt. Die Extraktion ist an das Eppendorf-Mikroliter-System 3000 angepaßt. Somit können in kurzer Zeit eine größere Anzahl Seren bearbeitet werden. Für eine Gesamtlipidbestimmung, beginnend mit dem Pipettieren der Probe, Extraktion usw. bis zum Auswiegen eines aliquoten Teiles des Extraktes, werden etwa $30 \mathrm{Min}$. benötigt. In einer Zeit von etwa 4 bis $5 \mathrm{Stdn}$. kann aus 6 Seren ein kompletter Lipidstatus mit Doppelbestimmung erstellt werden. Neben dem geringen Zeitaufwand ist hierbei auch die geringe Menge des benötigten $\mathrm{Ma}$ terials hervorzuheben.

Wir führen schon seit längerem mit dieser Methode Serumlipidbestimmungen für klinische Zwecke durch und glauben, daß sie durchaus von klinischen Laboratorien für Routineuntersuchungen eingesetzt werden kann.

\section{Methodik}

Extraktion der Lipide, quantitative Bestimmung

Reagenzien

Chloroform p. a., Methanol p. a.

Geräte

Eppendorf-Mikroliter-System 3000

$100 \mu l$ Spritze ${ }^{2}$ )

Cahn-Gram-Elektrowaage ${ }^{3}$ )

Heizplatte von $140^{\circ}$

Aluminiumschalen von $14 \mathrm{~mm}$ Durchmesser

Abdampfapparatur.

\section{Vorbereitung der Reaktionsgefäße}

Zur Entfernung von Weichmachern und niedrigen Oligomeren, die bei der nachfolgenden quantitativen gravimetrischen Bestimmung und Densitometrie zu Fehlern führen könnten, werden Pipettenspitzen und Reak-

1) Die Arbeit wurde durch ein Forschungsstipendium der NATO ermöglicht.

2) Terumo, ESGE oder Hamiltonspritze.

3) Anstelle der Cahnwaage können auch andere Mikrowaagen mit vergleichbaren Wägebereich eingesetzt werden. 
tionsgefäße der Firma Netheler und Hinz etwa 8 Stdn. im Soxhlet mit Chloroform:Methanol $=1: 1(\mathrm{v} / \mathrm{v})$ extrahiert und anschließend $3 \mathrm{Stdn}$. bei $90^{\circ}$ getrocknet. Längeres Extrahieren ist zu vermeiden, da das Plastikmaterial sonst brüchig wird. Pipettenspitzen und Reaktionsgefäße werden nur einmal verwendet.

\section{Ausfübrung}

Genau 20 (50) $\mu l$ Serum werden mit $500 \mu l$ Chloroform: Methanol $=8: 5$ (v/v) 1 Min. bei $20-25^{\circ}$ im verschlossenen Röhrchen gerüttelt und 2 Min. bei $15000 \mathrm{~g}$ zentrifugiert.

Der Uberstand wird mit einer $1000 \mu l$ Marburg-Pipette vorsichtig in ein zweites Röhrchen transferiert. Der Niederschlag wird nochmals mit $500 \mu \mathrm{l}$ Chloroform: Methanol 8:5 (v/v) 1 Min. gerüttelt und 2 Min. bei $15000 \mathrm{~g}$ zentrifugiert.

Die vereinigten UUberstände (etwa $1 \mathrm{~m} /$ ) werden mit $200 \mu \mathrm{l}$ Wasser versetzt, 30 Sek. gerüttelt und sofort zentrifugiert. Die wäßr. obere Phase wird nun vorsichtig mit einer $500 \mu l$ Pipette abgehoben und verworfen. Die untere Chloroformphase wird unter Stickstoff bei 50 bis $55^{\circ}$ im Wasserbad zur Trockne gebracht.

Die unter Stickstoff eingedampfte Lipidprobe wird in genau $100 \mu l$ (Mikroliterspritze) Chloroform:Methanol $2: 1(\mathrm{v} / \mathrm{v})$ durch kurzes Rütteln gelöst (es ist schnell zu arbeiten, damit keine Verluste an Lösungsmitteln durch Verdampfen entstehen).

$50 \mu l$ der Lösung werden auf ein vorher austariertes Aluminiumschälchen gegeben und bei $140^{\circ}$ auf den Trockenblock 2 Min. getrocknet. Die getrocknete Lipidprobe wird auf einer Cahn-Waage genau ausgewogen. Die Berechnung der Lipidmenge in $100 \mathrm{~m} /$ Serum erfolgt nach folgender Gleichung:

$$
\text { Gewicht }[\mu \mathrm{g}] \times 10(\times 4) \equiv \mathrm{mg} / 100 \mathrm{ml}
$$

Der Rest der Lipidprobe wird für die Dünnschichtchromatographie aufbewahrt.

Dünnschichtchromatographie der Serumlipide, Densitometrie $(8,10)$

\section{Reagenzien}

Chloroform p. a., Methanol p. a., n-Hexan zur Synthese

Schwefelsäure 10proz. ( $\nabla / v)$

Kieselgel Camag D-O4).

\section{Laifmittel}

1. Chloroform: Methanol: $\mathrm{H}_{2} \mathrm{O}=75: 25: 4(\mathrm{v} / \mathrm{v})$

2. Chloroform

3. Chloroform: $n-H \operatorname{exan}=1: 3(\mathrm{v} / \mathrm{v})$.

\section{Geräte}

Wägegläser mit NS 45, $90 \mathrm{~mm}$ hoch

Objektträger $25 \times 75 \mathrm{~mm}$

Joyce-Loebl Chromoscan

Heizplatten regelbat auf $100^{\circ}$ und $200^{\circ}$

4) Dic Wahl des Kieselgels mit Haftfestigkeit und Trenneigenschaft ist entscheidend für den Erfolg der Bestimmung. Anstelle von Kieselgel Camag D-O kann auch Kieselgel Fluka H F 254 mit etwas anderer Trenncharakteristik verwendet werden.
Sprühgefäße der Firma Desaga Heidelberg

Glaskapillaren zum Auftragen der Proben mit etwa 0,3 bis $0,5 \mathrm{~mm}$ innerem $\varnothing$

Anatomische Pinzette, Deckglaspinzctten.

\section{Herstellung der Mikrodünnscbichtplatten (10)}

Das Kieselgel wird zur Entfernung von Verunreinigungen, die bei der folgenden Densitometrie durch Untergrundbildung zu Störungen führen könnten, in der angegebenen Reihenfolge mit dem jeweils 3 fachen Volumen an Lösungsmittel gewaschen und anschließend abzentrifugiert.
$1 \times$ mit Wasser
$3 \times$ mit Methanol
$1 \times$ mit Chloroform: Methanol 1:1 (v/v)
$3 \times$ mit Chloroform

Das so gewaschene Kieselgel wird gleichmäßig in einer braunen Pulverflasche mit Glasstopfen $(250 \mathrm{~m} l)$ in Chloroform suspendiert, so daß etwa $35 \mathrm{~g}$ Kieselgel in $100 \mathrm{ml}$ Chloroform enthalten sind. Die Objektträger werden vor Gebrauch mit Chromschwefelsäure und bidest. Wasser gereinigt. Vor Beschichtung der Objektträger wird das Kieselgel in der Chloroformsuspension auf dem Magnetrührer oder von Hand bis zur völlig homogenen Suspension durchgerührt oder geschüttelt. Jeweils 2 Objektträger werden zum Beschichten ,,sandwich"-artig mittels Pinzette einmal in die KieselgelSuspension eingetaucht. Die noch feuchten, beschichteten Objektträger werden getrennt und an der Luft getrocknet (etwa 1 Min.). Nach dem Trocknen wird das Kieselgel an den Längsseiten der Objektträger zur Vermeidung von Randeffekten etwa $1 \mathrm{~mm}$ breit mit Daumen und Zeigefinger abgestreift.

Auf die so vorbereiteten Dünnschichtplatten wird das zu trennende Lipidgemisch mit einer Kapillare, $10 \mathrm{~mm}$ vom unteren Rand entfernt, bandenförmig aufgetragen, wobei darauf zu achten ist, daß die Schicht nicht unnötig verletzt wird.

\section{Chromatographie}

Die drei verschiedenen Laufmittel werden bis zu einer Höhe von $3 \mathrm{~mm}$ in die als Chromatographiegefäße dienenden Wägegläser eingefüllt. Das Gemisch Chloroform: Methanol: Wasser $=75: 25: 4(\mathrm{v} / \mathrm{v})$ läßt man etwa $1 \mathrm{~cm}$ über die Auftragstelle hinaus aufsteigen. Nach Abtrocknen an der Luft wird in Chloroform bis zur Mitte der Platte entwickelt. Nach Abtrocknen des Chloroforms wird in Chloroform: $n$-Hexan $=1: 3(\mathrm{v} / \mathrm{v})$ bis zum oberen Rand entwickelt. Nach Abtrocknen wird mit 10proz. (v/v) Schwefelsäure besprüht. Es ist hierbei darauf zu achten, daß das Sprühgefäß einen sehr feinen Nebel absprüht, damit die Kieselschicht nicht unnötig verletzt wird. Anschließend werden die Platten 2 Min. auf einem Heizblock bei $100^{\circ}$ getrocknet, danach 5 Min. lang bei $200^{\circ}$ auf dem Block geschwärzt. Bei Erwärmen auf $100^{\circ}$ werden Cholesterin und Cholesterinester durch die typische rotviolette Färbung erkannt (Salkowski-Reaktion). Zur weiteren Identifizierung der 


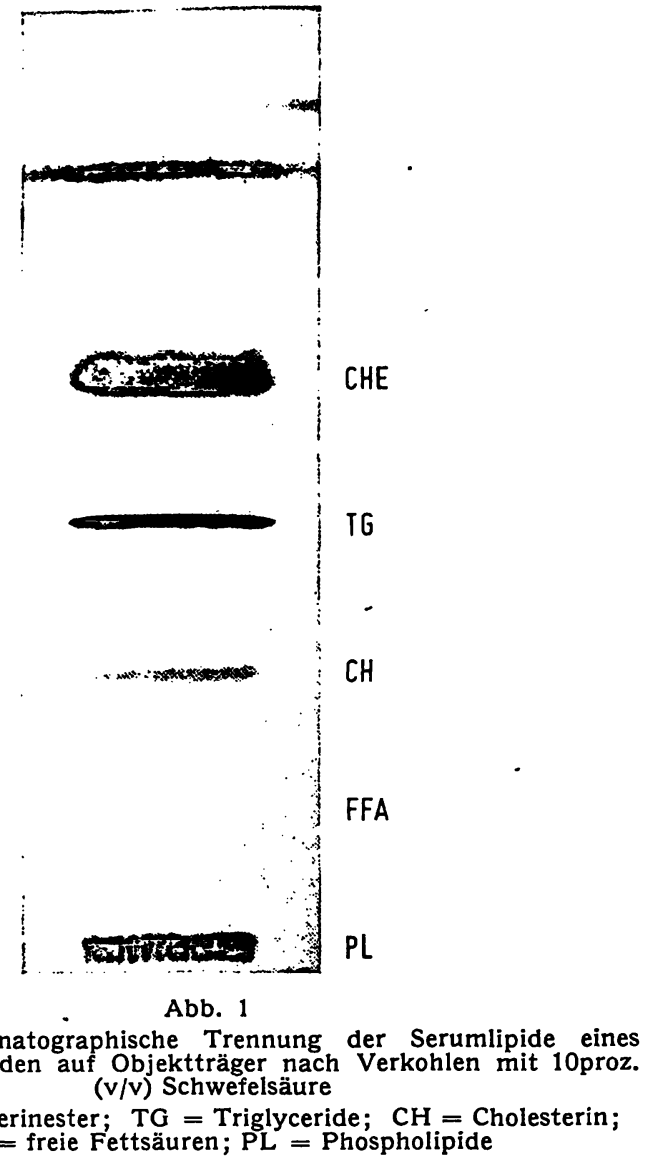

einzelnen getrennten Banden können spezifische Sprühreagenzien verwendet werden (11). Das nunmehr zur Densitometrie rorbereitete Plättchen zeigt die aufgetrennten Serumlipide in der Reihenfolge (von der Auftragstelle aus) Phospholipide, freie Fettsäuren, Cholesterin, Triglyceride und Cholesterinester (s. Abb. 1).

\section{Densitometrie}

Die quantitative Auswertung der Dünnschichtplatte erfolgt densitometrisch an einem Joyce-Chromoscan. Die erhaltenen Densitogramme werden mit dem im Gerät eingebauten Integrator, bei nicht idealer Nullinie mittels der Dreiecksmethode quantitativ ausgewertet.

\section{Sclbwärzungsfaktoren (2)}

Der Grad der bei der Behandlung mit Schwefelsäure auftretenden Schwärzung ist bei gleicher Lipidmenge unter den angegebenen Bedingungen nur abhängig von der Struktur des jeweiligen Lipids. Lipide mit kurzkettigen oder gesättigten Fettsäuren ergeben bei gleicher Menge eine geringere Schwärzung als solche mit hochungesättigten Fettsäuren. Zur Korrektur dieser Unterschiede müssen experimentell ermittelte Schwärzungsfaktoren berücksichtigt werden. Diese Faktoren werden mit den jeweiligen Flächenprozenten des Densitogrammes multipliziert und ergeben dann den prozentualen Anteil dieser Lipidkomponente.

Die angegebenen Korrekturfaktoren können für das freie und veresterte Cholesterin, Triglyceride, freie Fettsäuren mittels bekannter Bestimmungsmethoden (2)

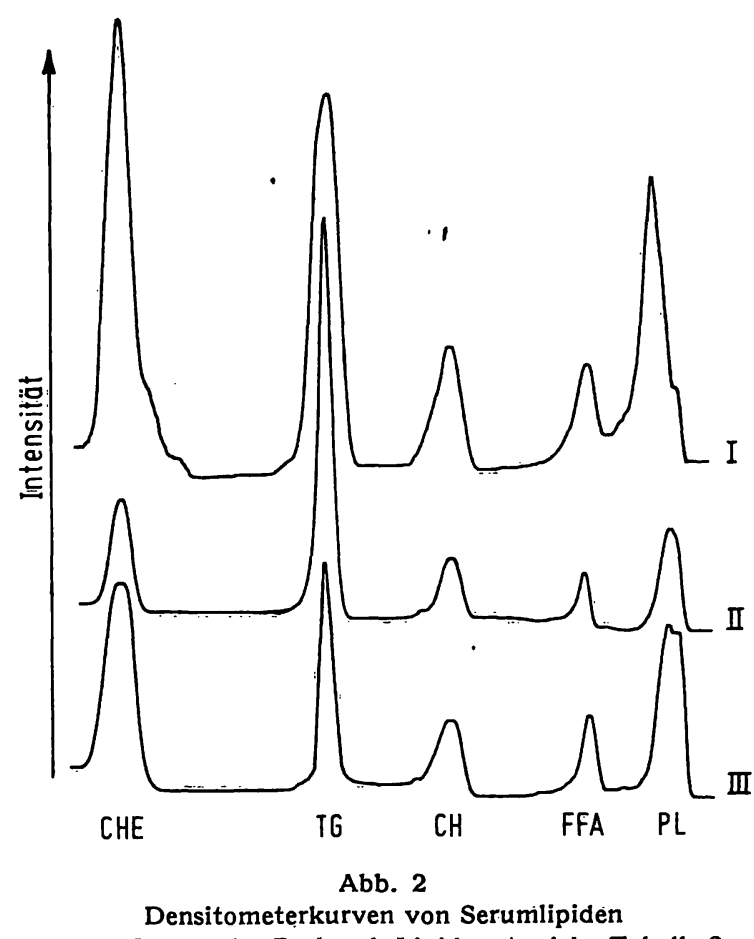

Kurve I gesunder Proband. Lipidwerte siehe Tabelle 2 Kurve II Pat. mit Hyperlipidaemie (Starke Vermehrung der Triglyceride). Lipidwerte siehe Tabelle 1

Kurve III Patient mit Hyperlipidaemie (Vermehrung des Gesamtcholesterins sowie der Triglyceride). Lipidwerte siehe Tabelle 1

überprüft werden. Für Serum ermittelte Korrekturfaktoren:

$\begin{array}{ll}\text { Cholesterin } & 1,00 \\ \text { Cholesterinester } & 1,01 \\ \text { Triglyceride } & 1,15 \\ \text { freie Fettsäuren } & 1,10 \\ \text { Phospholipide } & 1,55\end{array}$

Tab. 1

Verteilung der Serumlipide zweier Patienten mit Hyperlipidaemien (vgl. Abb. 2)

\begin{tabular}{lrcrc}
\hline & \multicolumn{2}{c}{ Kurve II } & \multicolumn{2}{c}{ Kurve III } \\
& $\%$ & mg/100 ml & $\%$ & mg/100 ml \\
\hline Cholesterinester & 18,3 & 370 & 30,6 & 400,9 \\
Triglyceride & 43,5 & 880 & 21,0 & 275,1 \\
Cholesterin & 11,3 & 229 & 10,3 & 134,9 \\
Freie Fettsäuren & 5,3 & 104 & 5,7 & 74,7 \\
Phospholipide & 21,6 & 436 & 32,4 & 424,4 \\
Gesamtlipide & 100 & 2019 & 100 & 1310 \\
\hline
\end{tabular}

\section{Fehlerbreite}

Die Bestimmung der Standardabweichung und des Variationskoeffizienten erfolgt nach den folgenden Formeln:

$$
\begin{gathered}
\text { Standardabweichung: } s=\sqrt{\frac{\sum_{1}^{n}(\overline{\mathbf{x}}-x)^{2}}{n-1}} \\
\text { Variationskoeffizient: } V=\frac{s \cdot 100}{\bar{x}}
\end{gathered}
$$

wobei $\quad x=$ Wert der Einzelmessung

$\overline{\mathbf{x}}=$ Mittelwert der Einzelmessungen

$\mathrm{n}=\mathrm{Zahl}$ der Einzelmešsungen 


\section{Variationskoeffizienten}

a) bei vorgegebener Lipidlösung

$$
\begin{aligned}
& \overline{\mathrm{x}}=121,1 \mu \mathrm{g} \\
& \mathrm{V}=0,82 \% \quad \mathrm{n}=10
\end{aligned}
$$

Abweichung vom Sollwert: 0,5\%

b) bei vorgegebenem Serum mit Extraktion

$$
\begin{aligned}
& \overline{\mathrm{x}}=168,2 \mu \mathrm{g} \\
& \mathrm{V}=1,8 \% \quad \mathrm{n}=10
\end{aligned}
$$

c) bei der Densitometrischen Bestimmung der Lipide aus dem Nüchternserum eines gesunden Probanden s. Tabelle 2 .
Tab. 2

Prozentuale Verteilung der Lipide eines Normalserums und Variationskoeffizienten. $n=10$

\begin{tabular}{cccccc}
\hline $\begin{array}{c}\text { Kom- } \\
\text { ponente }\end{array}$ & $\begin{array}{c}\text { Phospho- } \\
\text { lipide }\end{array}$ & $\begin{array}{c}\text { Freie } \\
\text { Fett- } \\
\text { săuren }\end{array}$ & $\begin{array}{c}\text { Chole- } \\
\text { sterin }\end{array}$ & $\begin{array}{c}\text { Trigly- } \\
\text { ceride }\end{array}$ & $\begin{array}{c}\text { Chole- } \\
\text { sterin- } \\
\text { ester }\end{array}$ \\
\hline $\begin{array}{c}\% \text { Gesamt- } \\
\text { lipid }\end{array}$ & 37,5 & 6,0 & 12,1 & 16,4 & 28,0 \\
$\begin{array}{c}\text { Variations- } \\
\text { koeff. }\end{array}$ & 5,1 & 10,0 & 8,0 & 4,0 & 2,3 \\
\hline V [\%] & $5 \%$ & & & & \\
\hline
\end{tabular}

Die von 8 unabhängigen geübten Experimentatoren ermittelten Fehlerbreiten liegen alle in demselben Bereich.

\section{Literatur}

1. Müller-SeIfert, Taschenbuch der medizinisch-klinischen Diagnostik. 69. Auflage. Verlag von J. F. Bergmann, München (1966). - 2. ZöLLNER, N. und D. EBerhagen, Untersuchung und Bestimmung der Lipide im Blut. Springer Verlag, Berlin, Heidelberg, New York (1965). - 3. Bang, J. Biochem. Z. 91, 86 (1918). - 4. Bloor, W. R., J. biol. Chemistry 16, 517 (1913/14). 5. Boyd, E. M., J. biol. Chemistry 143. 131 (1942). - 6. SEArCY,
R. C., J. L. Korotzer und L. M. Berquist, Clin. Chim. Acta, Amsterdam 8, 376 (1963). - 7. SPENY, W. M., Methods Biochem. Analysis 2, 83 (1955). - 8. van Gent, G. M., Z. analyt. Chem. 236, 344 (1968). - 9. Folch, J., M. Cees und G. H. Stanley, J. biol. Chemistry 226, 497 (1957). - 10. Pfeirer, J. J., Microchim. Acta 529 (1962). - 11. StafiL, E., Dünnschichtchromatography. 2. Aufl. Springer Verlag, Berlin (1967).
Prof. Dr. F. Zilliken Inst. f. Physiol. Chem.

d. Rhein. Friedrich-Wilhelms-Univ. 53 Bonn, Nußallee 11 